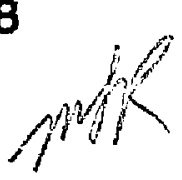

$$
\pm-18956
$$

PPPL-2178

NoTIEE

PQRTIOHS OF THIS REPOAT ARE GLLEGIQLE it has been reproduced from the bott available copy to permit the broatsos possibte avaifability.

OBSERVATION OF THE BACKHARD ELECTROSTATIC ION CTCLOTRON WAVE

By

J. Goree, M. Ono, and K.L. Tong

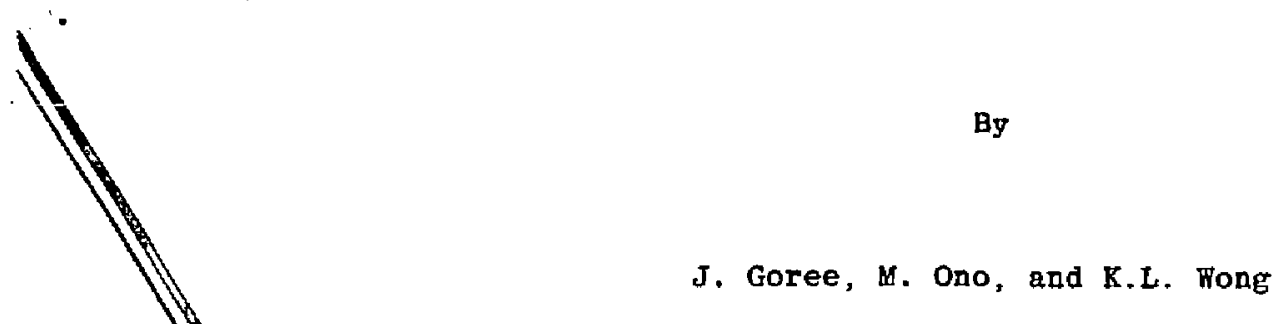

DECEMBER 1984

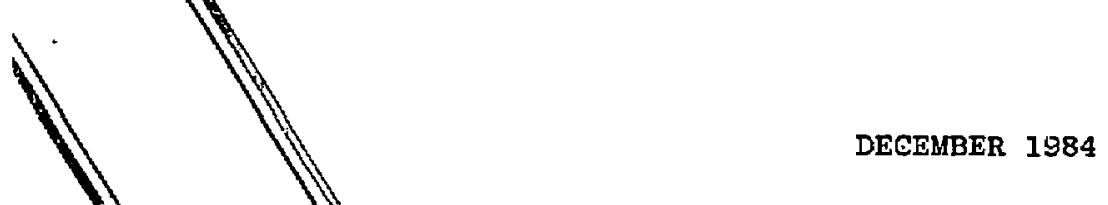

PRINCETON UNIV RTITIT

PRINCETON, NEW JRRSEY

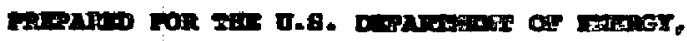

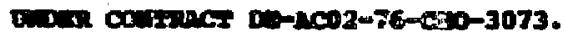


Thts report was prepared as an account of work sponsored by the United states Govornment. Nelther the United states nor the United States Department of Energy, nor any of their epployees, nor any of their contractors, subcontractors, or their employees, makeg any warranty, express or implted, or asalmes any legal liabtilty or responsibility for the accuracy, conpletenens or ugefulness of any infortation, apparatus, product or process discloged, or represents that itg use would not infringe privately owned rights.

Printed in the Untted States of America

Avallable from:

National Technical Information Service

U.S. Departrent of Comserce

5285 Port Royal Road

Springfield, virglnia 22161

Erice Printed Copy $\$$; Microflahe $\$ 4.50$

7qageg
$1-25$
$25-50$
$51-75$
$76-100$
$101-125$
$126-150$
$151-175$
$176-200$
$201-225$
$226-250$
$251-275$
$276-300$
$301-325$
$326-350$
$351-375$
$376-400$
$401-425$
$426-450$
$451-475$
$476-500$
$500-525$
$526-550$
$557-575$
$567-600$

NTIS

Selling Prica

$\$ 7.00$

\$8. 50

$\$ 10.00$

$\$ 11.50$

$\$ 13.00$

$\$ 14.50$

$\$ 16.00$

$\$ 17.50$

$\$ 19.00$

$\$ 20.50$

$\$ 22.00$

$\$ 23.50$

$\$ 25.00$

$\$ 26.50$

$\$ 28.00$

$\$ 29.50$

$\$ 37.00$

$\$ 32.50$

$\$ 34.00$

$\$ 35.50$

$\$ 37.00$

$\$ 38.50$

$\$ 40.00$

$\$ 41.50$
For documents over 600 pages, add $\$ 1.50$ for each additional 25-page increment. 


\title{
OBSERVATION OF THE BACKWARD ELECTROSTATIC ION CYCI.OTRON WAVE
}

J. Goree, M. Ono, and K. L. Wong

Plasma Physics Laboratory, Princeton University

Princeton, New Jersey 08544

ABSTRACT

PPPL- -2178

DEB5 005340

\begin{abstract}
The backward branch of the eilectrostatic ion cyclatron wave has been observed, we believe, for the first time. The wave, which was driven by a phased antenna structure inserted in a neon plasma, exists in the parameter ranges $2 T_{i} / m_{i} \ll\left\langle a / k_{i}\right)^{2} \ll 2 T_{e} / m_{e}, n \Omega_{i}<\omega<(n+1) \Omega_{i}, T_{e}>T_{i}$, and $\omega_{p^{i}}>$ $\Omega_{j}$. Double-tip probe interferonetry data agree with the theoretical dispersion relation.
\end{abstract}

\section{DISCL AIMER} This report was prepared as an account of work sponsored by an agency of the United Slates Government. Neither the United States Gorernment nor any agency thes liability or responsibility for the aceuracy, completeness, or usefuiness of any information, apparatus, preds. Refer-

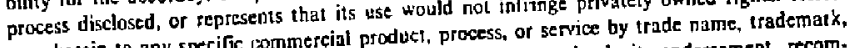
ence hercin to any specilic commercial product, process, or serich is endorsement, recom. manufactuter, or otherwise does nol necessacily constilute or imply is endorsement, secomiews mendation, or favoring by the United States Government or any agency thereof These of the

and epinions of authors expressed herein do not 
The electrostatic ion cyclotron wave is the hot magnetized plasma mode with its frequericy near an ion gyrofrequency harmonic and a phase velocity parallel to the magnetic field $w / k_{\Downarrow}$ less than the electron thermal velocity, but greater than the ion therinal velocity. It has also been called the neutralized ion Bernstein wave. I

The wave was discovered by D'Angelo and Motley $(19 Q 2),{ }^{2}$ who observed tne acousticlike forward wave at the fundamental frequency in a cold alkali plasma. Drumond and Rosenbluth ${ }^{3}$ attributed thei- observation to a kinetic instability associated with parallel electron difift. Lominadze and Stepanov $(1965)^{4}$ introduced finite Larmor radius (FLR) effects into theory, revealing for the first time this mode's backward branch.

These are the criteria which specify the electrostatic ion cyclotron wave:

$$
\begin{aligned}
& \sqrt{\frac{2 T_{i}}{m_{i}}} \ll \frac{\omega}{k_{11}} \ll \sqrt{\frac{2 T_{e}}{m_{e}}}, \\
& m_{i}<\omega<(n+1) s_{i}, n \geq 1,
\end{aligned}
$$

and

$$
\omega_{p i}>s_{j} \text { and } T_{e} \tilde{>} T_{j}
$$

The real solutions of the dispersion relation of the electrostatic ion cyclotron wave generally show two possible values for $k_{\perp}$ for a given frequency. Except for w very near $n_{i}$, the shorter wavelength solution is a backward wave, i.e., the wave number vector component $k_{\perp}$ has the direction 
opposite that of the group velocity. Several experiments have been reported on the forward branch, 5-7 and Schmitt was able to observe effects of ion cyclotron harmonics through antenna loading measurements. ${ }^{8}$ However, observation of the backward branch was not reported in these experiments. This mode should be distinguished from the pure ion Bernstein wave, which is also backward, but is characterized by w/k $\gg \sqrt{2 T_{\mathrm{e}} / \mathrm{m}_{\mathrm{e}}}$, and has no forward branch. 1,9

For electrostatic waves, the collisionless dispersion relation can be expressed ${ }^{10}$ as $D\left(\omega, k_{\perp}\right)=0$, where

$$
0=k_{1}^{2} k_{x x}+2 k_{\|} k_{1}{ }^{k_{x z}}+k_{\|}{ }^{2} k_{2 z}
$$

and the dielectric tensor elements $k_{x x}$ and $k_{z z}$ are

$$
\begin{aligned}
& k_{x x}=1+\frac{\omega_{p e}^{2}}{\Omega_{e}^{2}}+\frac{E}{j} \frac{\omega_{p j}^{2}}{k_{b} \omega} \frac{e^{-\lambda} j}{\lambda_{j}} \sqrt{\frac{m_{i}}{2 T_{j}}} \underset{n=-\infty}{+\infty} n^{2} I_{n}\left(\lambda_{j}\right) Z\left(\zeta_{n}^{j}\right) \\
& k_{z z}=1+\frac{2 \omega_{p e} e^{2}}{k_{y}{ }^{2}} \frac{m_{e}}{2 T_{e}}\left[1+\frac{\omega}{k_{y}} \quad \frac{m_{e}}{2 T_{e}} z\left(\zeta_{0}^{e} i\right] .\right.
\end{aligned}
$$

and

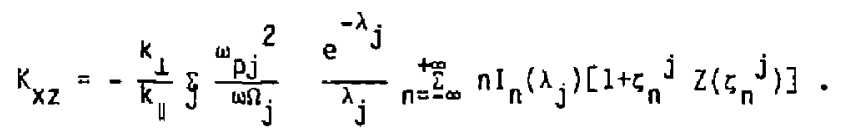


Here, $\lambda_{j}=k_{1}{ }^{2} T_{j} / m_{j} \Omega_{j}{ }^{2}, j$ designates the ion species, $I_{n}$ is the modified Bessel function, $\zeta_{n}{ }^{k}=\left(\omega-n \Omega_{k}\right)\left(\pi_{k} / 2 T_{k}\right)^{1 / 2}$, and $Z$ is the plasma dispersion function. It was assumed that $\omega \ll \Omega_{e}, \lambda_{e} \ll<1$, and that the distribution runctions are isotropic, nondrifting Maxwellians.

By specifying the parameters of inequalities (1) and (2), this dispersion relation yields the electrostatic ion cyclotron wave solutions. Except for the acoustic wave 1 imit, ${ }_{3}^{11} \lambda_{j} \ll 1$, the roots of the dispersion relation are most easily computed numerically. For a single ion species, the wave is forward for small values of $\lambda_{j}$ and backward for $\lambda_{j}>1$. For all values of $\lambda_{i}$, the electrostatic ion cyclotron wave is prone to severe ion and especialiy electron Landau damping. The first term of Eq. (3) depends mostly on ion kinetics and one finds in it the FLR effects which are responsible for the backward wave. The second term is negligible and the thind term, due to electrons, dominates for the forward wave.

The experiment ran on the ACT-I toroidal device 12 with a verticaliy uniform magnetized plasma with warm ions. A singly ionized heavy ion species, $\mathrm{Ne}^{+}$, was used to satisfy relations (1) and (2). Observation of the backward bianch may have been unreported previously because it is difficult to satisfy these relations, to obtain warm ions, and to overcome Landau damping. An antenna structure, constructed of two blades of molybdenum plate attached to 1-mn tungsten rod, was inserted into the plasma. The blades were parallel to the magnetic field, in a vertical plane, as shown in Fig. 1.

An rf signal of several volts was applied to the antenna, the two blades phased at $180^{\circ}$ to create a $k_{g}$ spectrum peaked at $1.0 \mathrm{~cm}^{-1}$. The wave launched in the plasma was detected by an rf double-tip Langmuir probe which was scanned radially to measure $k_{\perp}$ by interferonetry. The probe could pass 
through the gap between antenna blades, where a strong nonpropagating disturbance was found in a liem thick laye-. Outside this layer, the electrostatic ion cyciotron wave was observed.

The antenna blades lay perpendicular to the toroidal magnetic field gradient. The direction of this gradient affected the antenna coupling to the wave and the backward wave was usually found on the low fieid side of the antenna. Using probe interferometry made with an rf phase sensitive detector, we compared two radial interferometry traces, with the signal delayed by $0^{\circ}$ and $90^{\circ}$, to determine the direction of $k_{1}$. $k_{\perp}$ points in the direction in which the peaks and valleys of the $0^{\circ}$ trace appear to be shifted from those of the $90^{\circ}$ trace. The group velocity direction is aiways outward from the antenna and the backward wave is identified when $k_{\perp}$ is directed in toward the antenna. Such behavior is observed in the interferometry traces shown in Fig. 2. The backward wave propagates on the low field side of the antenna, and the forward wave on the high field side.

By taking data for many frequencies, we obtained the expe-ilinental dispersion relation shown in Fig. 3. A theoretical solution, Eq. (3), is also shown and the experimental data fit it well.

We thank T. H. Stix for making helpful suggestions regarding the manuscript and W. Kineyko and J. Taylor for able technical assistance. This work is supported by the U.S. Department of Energy Contract No. DE-ACO2-7 6CHO-3073. 
References

1J. P. M. Schaitt, Phys. Rev. Lett. 31,982 (1973).

$2_{N}$. D'Angelo and R. W. Motley, Phys. Fluids 5 , 633 (19Q8),

3. F. Drummond and M. N. Rosenbluth, Phys. Fluids 5, 1507 (1962).

${ }^{4}$ D. G. Lominadze and K. N. Stepanov, Sov, Phys. -Tech. Phys. 9, 1408 (1965).

5. Hirose, 1. Alexeff, and W. D. Jones, Phys. Fiuids 13, 2039 (1970).

6E. R. Ault and H. [kezi, Phys. Fluids $\underline{13}, 2874$ (1970).

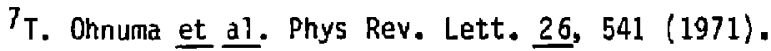

8 J. P. M. Schmitt, Phys. Fluids 15,2057 (1972).

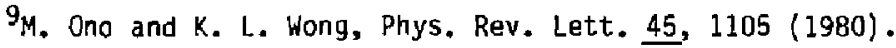

${ }^{10}$ T. H. Stix, Theory of Plasma Waves, Ch.9, (McGraw-Hill, N.Y., 1962).

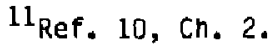

12K. L. Wong, M. Ono, and G. Wurden, Rev. Sci. Instrum. $\underline{53}, 409$ (1982). 


\section{Figure Captions}

Fig. 1. The geametry of the antenna, drawn to scale, as viewed from the side of the torus. Plasma is shown shaded.

FIG. ? Probe interferometry traces of the electrostatic ian cyclotron wave in a neon plasma. The wave was launched with frequency $\omega / 2 \pi=440 \mathrm{KHz}\left(\omega / \Omega_{j}=1.33\right)$ on the fundamental mode branch. The traces were made while delaying the probe signal by either $0^{\circ}$ or $90^{\circ}$ compared to the oscillator driving the antenna. The direction of $k$ points from valleys in the $90^{\circ}$ trace to valleys in the $0^{\circ}$ trace, and from hills in the $90^{\circ}$ trace to hills in thr: $0^{\circ}$ trace. The forward wave, by definition, has $k_{\perp}$ in the same direction as the group velocity, which is always away from the antenna. The backward wave is seen at the left, on the low field side of the antenna. The strong nompropagating disturbance between the antenna blades is not shown, for clarity.

Fig. 3. The dispersion relation of the electrostatic ion cyclotron wave in the same neon discharge used in Fig. 2. The solid curve is a numerical solution assuming $k_{\|}=1.0 \mathrm{~cm}^{-1}, T_{e}=2.1 \mathrm{eV}, T_{j}=0.4$ eV. 
\#84X0785

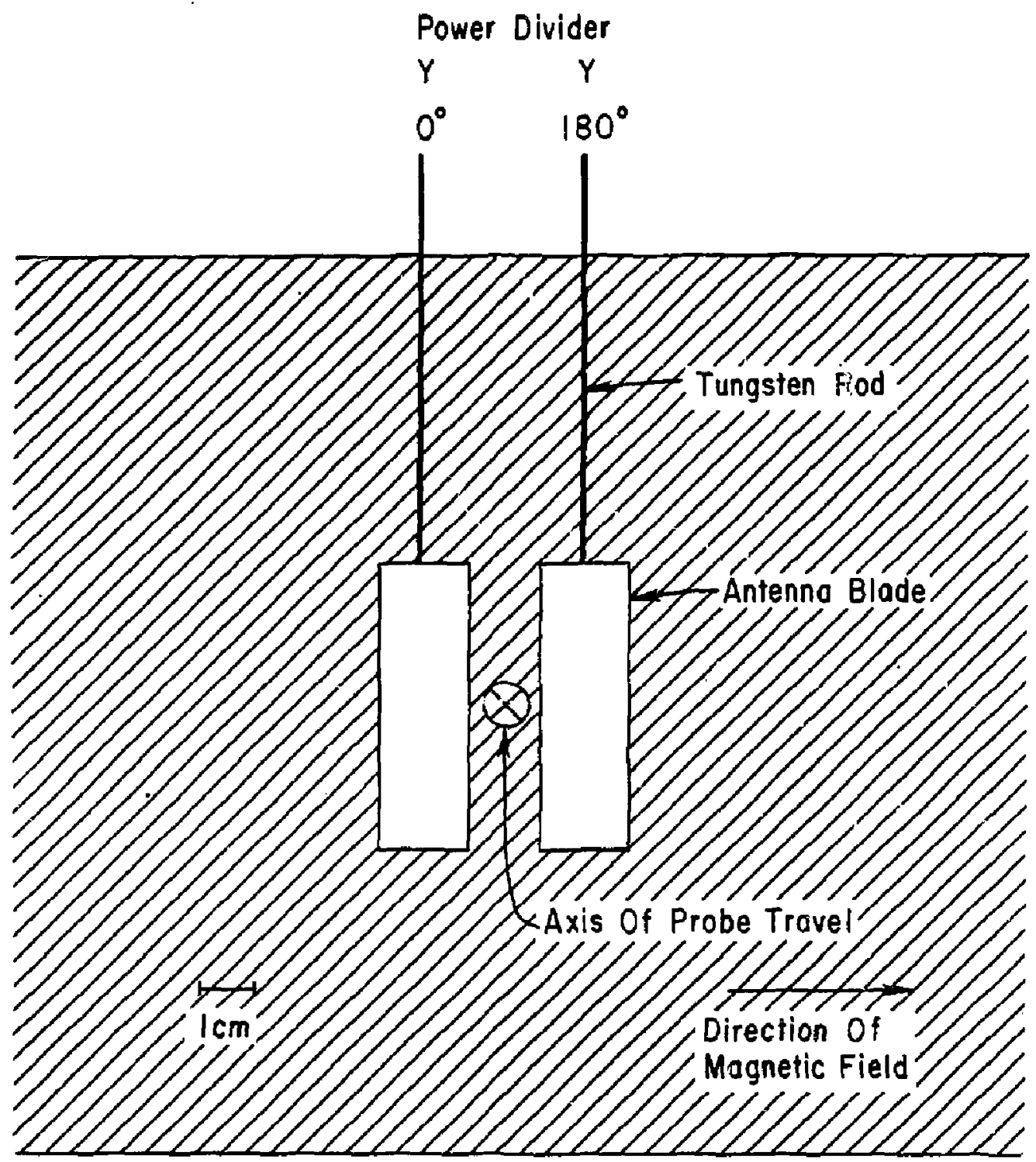

Fig. 1 


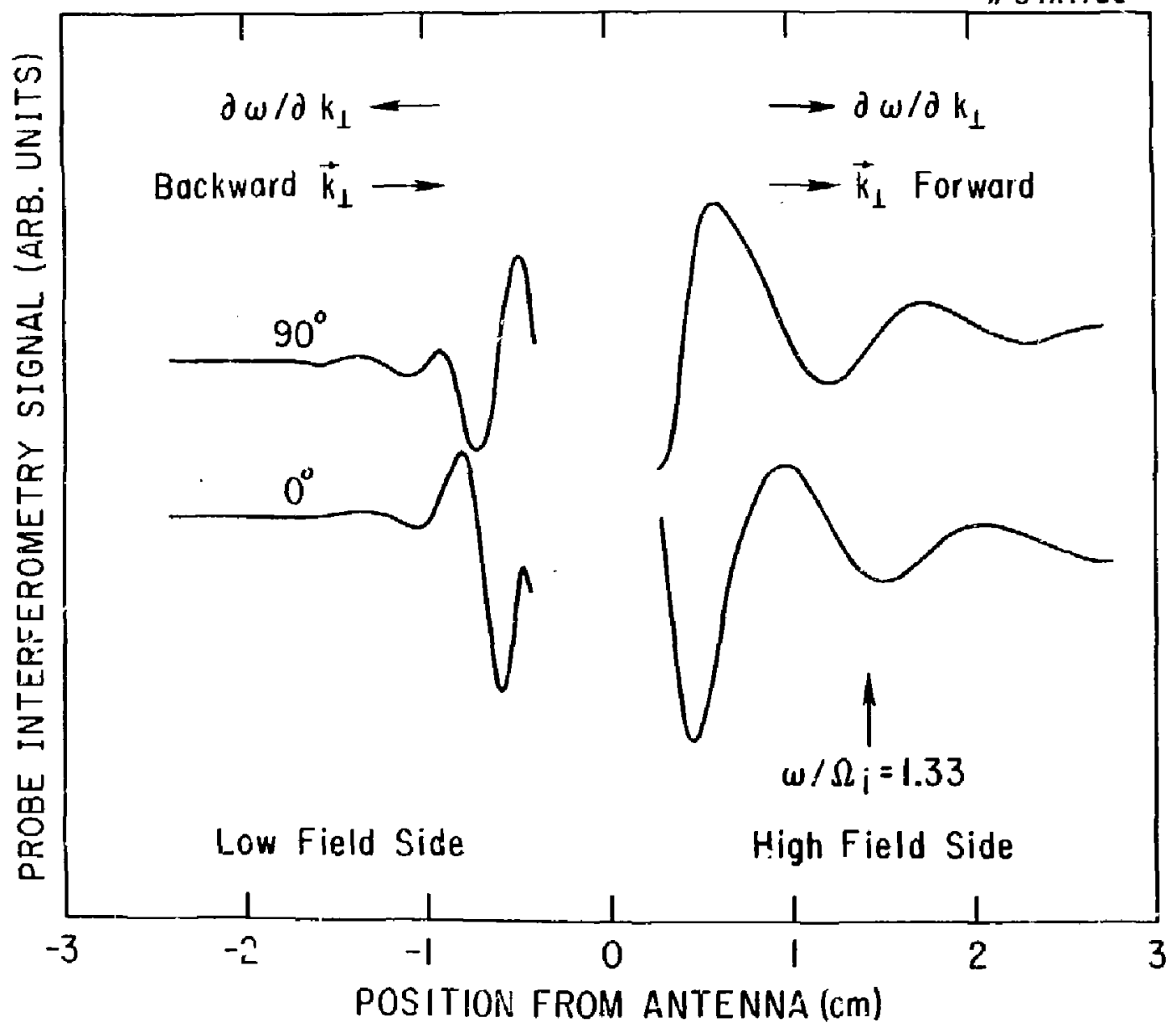

Fig. 2 


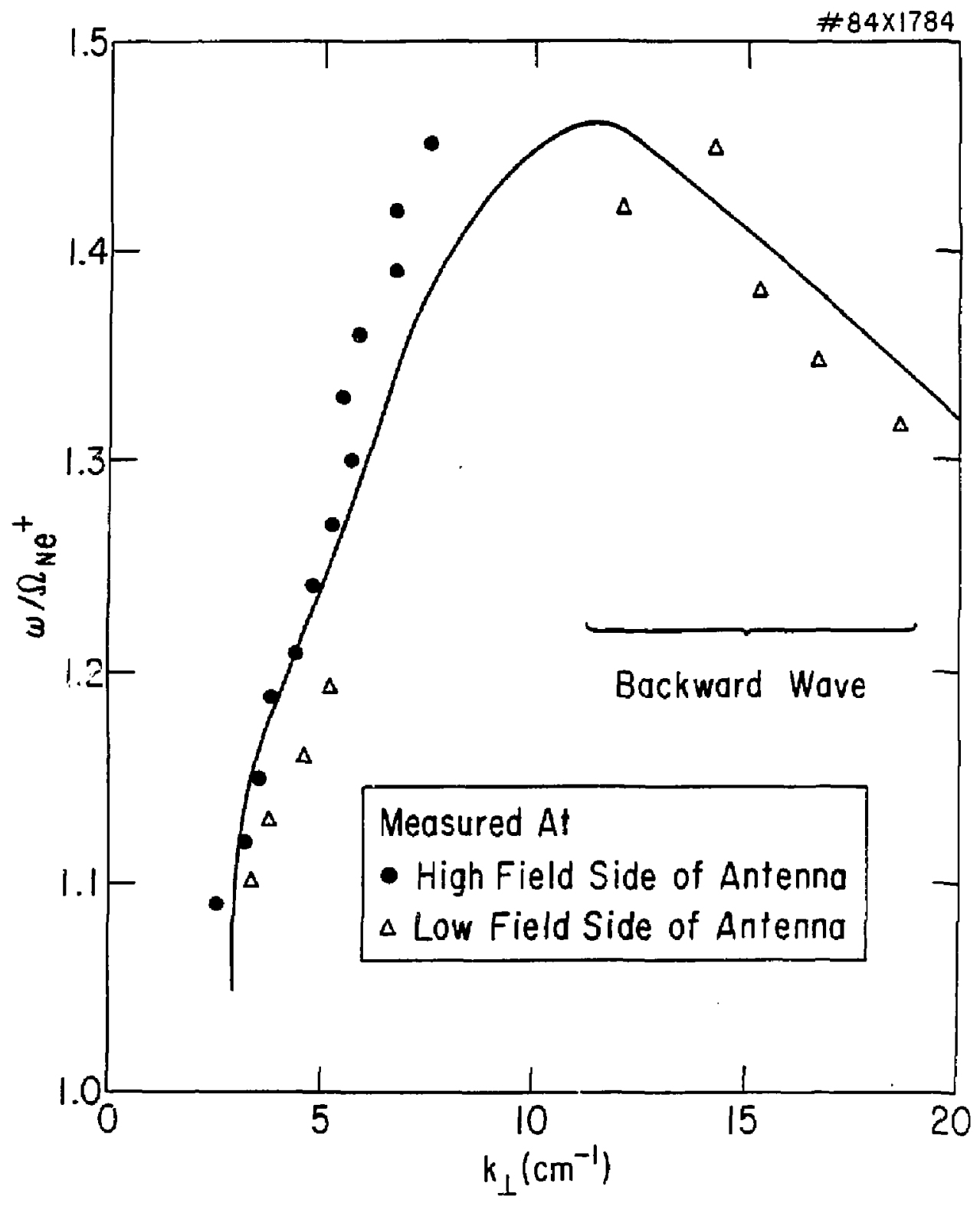

Fig. ? 


\section{EXTERALL DISTRIEUTION IH ADDITION TO TIE UC-20}

Plasmo Res Lob, Austre nat'l Univ, austral ia Or. Frank J. Paolonl, Univ of wollongong. AUSTRAL iA Prof. I.R. Jones, Fllnders UnlY., AUSTRAL IA Pi.of. M.H. Erennen, Univ Syoney. AUSTRAL iA Prot. F. Cep, Inst Theo Phys, austria Prof. Front: Verheest, inst theoretisehe, BELGIUM Dr. D. Paiumbo, Og XII fusion Prog, eELGILM Ecale Rayale Millitalre, Lab de Phys Plesmas, eElgium Mr. P.H. Sakanaka, Univ Estadual, BRAZIL

Dr. C.fi. James, Univ of Alberte, CANRDA

Prot. J. Teicnmenn, Univ of Montreal, CAMADA Dr. H.M. Skarsgara, Unlv of Sosketenemon, CAnMDa Prot. S.R, Sreenlyasan, Unlversity of Celgory, CANADA Frot. Tudor th. Johnston, laks-Energle, CANADA Dr. Hennes Bornard, Unir British Colukibla, CAHADA Dr. M.F. Bochynskl, MPB Technologies, Ire., CANAOK Znongmu LI, Sit Inst Physlçs, CHINA

librory. Ts ing Hua Univarsity. CHIma

LIbrarlan, Instlitute of Physles, CHIni inst Plesme Phys, Acadomia Sinlea, CHIRA Dr. Petar Lukec, Komonskeho Unlv, CZEChoslovakiA The Llorarlan, Cultian Lesoratory, ENGLAND Frot. Schetzmon, Doservatoire de Nlce, FRance J. Rodet, CEN-P6, FaAnCE

AH Dupas Llbrary, AM Dupas Ll brary, FRAKCE Dr. Tom Mual, headomy Bloliographic, HONG KONG Preprint LIbrory, Cent Res Inst Phys, HumGafy Or. S.K. Trehan, Panjad Unlvarsity, INDIA

Dr. Indra, Mohan LaI Das, Banaras HInalu Univ, INDIA Dr. L.K. Chavda, South Gujeret Unlv, INDIA Dr. R.K. ChhajlanI, Yar Ruchl Marg, INDIA P. Ko., Physical Research Lat, InDIA Dr. Palllid Rosenau, Isroel Ins: Tech, ISRAEL Prat. S. Cuparmon, Tel Aviv University, ISRAEL Frot, G. Rostegni, Ualv Di Padova, ITALY Lierorion, InT'l CTr Theo Phys: ITALY miss clello de Palo, assoc EURATOM-CNEN, ItALY EIDIiotece, deI CNR EURATON, ITALY

or. M. Yometo, Toshide Res \& Dev, Japan

Prof. M. YostikBwa, JAERI, TOKbi Res Est, JAFAN

Prot. T. Uchida, University of Tokyo, JAPAN

Reseerer Into Canter, Hagoya University, JAPAN

Frot. Kyoji Nishlkeve, Univ of MIroshime, JAPAN

Prct. Sigoru Norl, JAERI, JAPAN

LIbrary, Kyoto Un iversity, JAPAN

Erot. IchIrc Kanakami, NIhon UnIv, JAPAN

Frot. Setoshi ltoh, Kyushu Unlvarsity, JAPAN

iecn Into Oivision, Korod Atomic Enorgy. KOREA

Dr. R. Englenc, Clvaec Unlversitario, MExico

Bibliothuen, Fom-l nst Visor Plasme, METhERLANDS

Prot. E.5. :Iley, Unlversity of walketo, NEw ZEALAND

Dr. Suresh C. Snarmo, Univ of Colabar, MIGERIA
Praf. J.A.C. Cabral, Inst Suparlor Tach, PORTUGal Dr. Octoulon Petrus, ALI CLeA UnIversity, ROMANIA Prof. M.A. Hellberg. Unlversity si Natal, SO AFRICA Dr. Johan de Villlers, Atomic Enorgy Bo, SO AFRICA Fusion Oly, LIbrary, JEN, SPAIN

Prot. Hans wilnelinson, Cholmars Univ Tech, SwEDEN Dr. Lennert Stonflo, Unlvarsity of MEA, SWEDEN Llbrary, Royal Inst Toch, SWEDEN

Dr. Er Ik T. Kerison, UDpselo UnIversitat, SWEDEN Contre de Rechorehesen. Exole Poirtech fod, SWITZERLAND Dr. W,L, We Ise, Nat'l l'ur Stond, USA Dr. W.M. Stacey, Georg inst Toeh, USA Dr. 5.T. Wu, UnIr Alebema, USA

Prof. Normen L. Oleson, Untus 5 Floride, USA Dr. Benjemln Ma, IOUa Stato UnIv, USA Prof. Magne Krlstiansen, Taxas Togm UnIV, USA Dr. Raymons Asker, Auburn UnIv. USA Dr. Y.T. Talok, Kharkov Phys Tuen Ins, USSR Dr. D.D. Ryutov, Siberian Aceo Sci, USSF Di. G,A. Ellseer, Kurchator Institute, ISSR Dr. V.A. Glukhikh, Inst Elactrodhysled, USSR Institute Gon. Physics, USSR

Prof. T.J. Boyd. Unir Colioge $N$ Woles, WMLS Or. K. Sehindier. Ruhr Universitat, M, Geramaly Huelegr Res Estob, Julloi LTd, W. GEPMANY

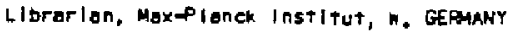
Dr. H.J. Keoppler, Universlty Stuttgert, H. GePanaw Bibl tothok, Inst Plosmotorschung. H. GePaANy 